Jurnal SPORTIF: Jurnal Penelitian Pembelajaran

Vol. 6 No. 1, April 2020, pp. 59-68

doi $\mathrm{https} / / /$ doi.org/10.29407/js_unpgri.v6i1.13872

\title{
Pengaruh suhu dan kelembaban terhadap vo2max pada atlet PPLP se-Pulau Jawa, Indonesia
}

\section{The effect of temperature and humidity on vo2max of PPLP athletes in Java, Indonesia}

\author{
Tommy Apriantono1, Indria Herman², Agung Dwi Juniarsyah', \\ Muhamad Fahmi Hasan', Sri Indah Ihsani ${ }^{1}$, Iwa Ikhwan Hidayat', \\ Imam Safei ${ }^{1}$, Bagus Winata ${ }^{1}$, \& Ilham Hindawan ${ }^{1}$ \\ ${ }^{1}$ Sekolah Farmasi, Institut Teknologi Bandung, Jl. Ganesha No.10, Lb. Siliwangi, \\ Bandung, West Java Province, 40132, Indonesia \\ ${ }^{2}$ Department of Mechanical Engineering, Institut Teknologi Bandung, Jl. Ganesha No.10, \\ Lb. Siliwangi, Bandung, West Java Province, 40132, Indonesia
}

Received: 3 December 2019; Revised: 10 February 2020; Accepted: 13 March 2020

\begin{abstract}
Abstrak
Efek dari lingkungan yang panas pada kinerja aerobik belum didokumentasikan dengan baik. Suhu dan kelembaban suatu lingkungan berpengaruh terhadap fisiologis tubuh dan dapat memengaruhi penampilan fisik, serta proses oxygen intake $\left(\mathrm{VO}_{2 \mathrm{Max}}\right)$ yang kurang optimal. Hal ini menimbulkan sebuah pertanyaan apakah suhu lingkungan dapat berpengaruh terhadap kondisi tubuh pada saat berolahraga. Dengan demikian tujuan dari penelitian ini adalah untuk menguji efek suhu lingkungan yang berbeda terhadap $\mathrm{VO}_{2 \max }$ pada atlet PPLP se-Pulau Jawa Indonesia. Penelitian ini menggunakan metode studi observasional, di mana peneliti hanya melakukan observasi pada satu saat, tanpa memberikan intervensi pada variabel yang akan diteliti. Subjek dalam penelitian ini terdiri dari 80 Atlet PPLP se-Pulau Jawa. Di antaranya yaitu; Jawa Tengah (20 Atlet), Jawa Timur (20 Atlet), Jawa Barat (20 Atlet) dan DIY Yogyakarta (20 Atlet). Hasil penelitian ini menunjukkan bahwa $\mathrm{VO}_{2 \max }$ secara signifikan dapat berkurang pada suhu dan kelembaban $34^{\circ} \mathrm{C} / 70 \%$ dan $32^{\circ} \mathrm{C} / 60 \%$ dibandingkan dengan suhu dan kelembaban $23^{\circ} \mathrm{C} / 69 \%$ dan $31^{\circ} \mathrm{C} / 50 \%$. Kinerja aerob sangat dipengaruhi oleh fungsi kardiovaskular. Lingkungan yang panas meningkatkan aliran darah kulit yang mengubah fungsi kardiovaskular. Sehingga hal ini dapat memengaruhi penurunan terhadap oxygen intake $\left(\mathrm{VO}_{2 \max }\right)$.
\end{abstract}

Kata kunci: atlet, kelembaban, suhu, $\mathrm{VO}_{2 \max }$.

\begin{abstract}
The effects of a hot environment on aerobic performance study have not been well documented. The temperature and humidity of an environment affect the body's physiology, influence physical appearance, and affect the less advantageous process of oxygen intake (VO2Max). Hence, a question arises in this study is the effect of environmental temperatures on the body condition while exercising. Accordingly, the purpose of this study is to examine the effect of different environmental temperatures on VO2max of PPLP (Students education and training center/pusat pendidikan dan latihan pelajar) athletes in java island, Indonesia. This study employs an observational study method, in which the researcher only observes at one time, without intervention on the examined variables. The subjects are 80 PPLP athletes from Java, specifically 20 Athletes
\end{abstract}

Correspondence author: Imam Safei, Institut Teknologi Bandung, Indonesia.

Email: imamsyafei25@gmail.com 
of Central Java, 20 Athletes of East Java,20 Athletes of West Java and 20 Athletes of Yogyakarta. The results of this study indicate that VO2max is significantly decreased at the air temperature of $34^{\circ} \mathrm{C}$ with relative humidity of $70 \%$ and the air temperature of $32^{\circ} \mathrm{C}$ with relative humidity of $60 \%$ compared to the air temperature of $23^{\circ} \mathrm{C}$ with relative humidity of $69 \%$ and the air temperature of $31^{\circ} \mathrm{C}$ with relative humidity of $50 \%$. Aerobic performance is intensely influenced by cardiovascular function. A hot environment increases the blood flow of the skin, which changes cardiovascular function. Consequently, this decreases oxygen intake (VO2max).

Keywords: temperature, humidity, athletes, $\mathrm{VO}_{2 \max }$.

\section{PENDAHULUAN}

Suhu dan kelembaban di suatu lingkungan merupakan faktor penting yang harus diperhatikan dalam berolahraga. Temperatur suhu dan kelembaban sekitar memiliki pengaruh secara signifikan terhadap respons fisiologis manusia ketika melakukan aktivitas fisik (Tyka, Palka, Tyka, Cison, \& Szygula, 2009). Kombinasi suhu lingkungan yang tinggi dan kelembaban relatif tinggi $(\mathrm{RH})$ menciptakan tekanan besar bagi altet ketika latihan dalam kondisi tersebut (Sacha \& Quinn, 2011). Hilangnya cairan tubuh yang berlebihan dapat berakibat fatal terhadap kinerja fungsi tubuh, yang tentunya harus segera dikembalikan ke tingkat awal (rehidrasi). Kehilangan cairan tubuh ini dapat memengaruhi penampilan fisik, memperberat kerja jantung, serta proses oxygen intake $\left(\mathrm{VO}_{2 \max }\right)$ yang kurang optimal (Cheuvront, Kenefick, Montain, \& Sawka, 2010).

Sebagian penelitian melaporkan bahwa suhu lingkungan yang tinggi secara signifikan dapat mengurangi $\mathrm{VO}_{2 \max }$ dan merusak kinerja aerobik (Mintarto \& Fattahilah, 2019). Di sisi lain suhu yang panas juga dapat mengurangi $\mathrm{VO}_{2 \max }$ pada pria dan wanita dan hal ini sebanding dengan peningkatan suhu inti dan suhu kulit (Arngrímsson, Petitt, Borrani, Skinner, \& Cureton, 2004). Sebaliknya, penelitian lainnya juga menunjukkan bahwa suhu lingkungan yang tinggi tidak berpengaruh pada $\mathrm{VO}_{2 \max }$ (Zhao et al., 2013). Namun, Penelitian sebelumnya tidak melaporkan inti dan suhu kulit dan tidak menyelidiki efek dari lingkungan yang berbeda pada $\mathrm{VO}_{2 m a x}$; hal ini sulit untuk membuat perbandingan yang tepat antara pengaruh dan tidak pengaruh nya suhu terhadap $\mathrm{VO}_{2 \max }$ (Snell, Stray-Gundersen, Levine, Hawkins, \& Raven, 2007). Ada 
kemungkinan bahwa dalam studi ini, suhu inti atau suhu kulit tidak cukup tinggi untuk menurunkan $\mathrm{VO}_{2 \max }$.

Hanya ada satu laporan tentang efek tingkat kelembaban yang berbeda pada $\mathrm{VO}_{2 \max }$. Stensrud, Berntsen, \& Carlsen (2006) melaporkan bahwa $\mathrm{VO}_{2 \max }$ meningkat secara signifikan dari $40 \%$ menjadi $95 \% \mathrm{RH}$ pada kondisi termoneutral $\left(20^{\circ} \mathrm{C}\right)$ pada subjek dengan bronkokonstriksi yang diinduksi oleh olahraga. Namun, masih belum jelas apakah $\mathrm{VO}_{2 \max }$ dipengaruhi oleh suhu lingkungan yang meningkat dalam kombinasi dengan $\mathrm{RH}$ tinggi atau dengan $\mathrm{RH}$ rendah dibandingkan dengan kondisi termoneutral pada atlet. Studi sebelumnya melaporkan bahwa kinerja uji anaerob Wingate tidak dipengaruhi oleh kondisi panaskering atau panas-basah, dibandingkan dengan lingkungan kontrol. Hasil ini menunjukkan kondisi kelembaban yang relatif berbeda tidak memengaruhi $\mathrm{VO}_{2 \max }$ atau kinerja uji anaerob Wingate di lingkungan yang panas (Taylor et al., 2002). Mungkin hal ini disebabkan karena suhu di daerah tersebut tidak terlalu panas.

Indonesia merupakan negara yang beriklim tropis dengan suhu dan kelembaban yang tinggi. Selama latihan dalam kondisi panas (dan terutama pada kesehatan reproduksi tinggi), gradien suhu inti ke kulit kecil dan transfer panas konvektif yang diperlukan membutuhkan peningkatan besar dalam aliran darah kulit (Sandi, 2014). Peningkatan aliran darah kulit akan memengaruhi fungsi kardiovaskular dengan mengurangi volume darah sentral dan volume stroke dan dengan mengganggu aliran darah otot (Gisolfi, 1983). Namun, efek dari suhu lingkungan yang tinggi dan tingkat kelembaban yang relatif berbeda pada kinerja latihan aerobik dan anaerob tidak terlalu diperhatikan. Sehingga hal ini menimbulkan sebuah pertanyaan apakah suhu lingkungan dapat berpengaruh terhadap kondisi tubuh pada saat berolahraga?

Dengan demikian tujuan daripada penelitian ini adalah untuk mengetahui seberapa besar efek suhu lingkungan yang berbeda terhadap $\mathrm{VO}_{2 \max }$ pada atlet PPLP se-Pulau Jawa Indonesia. Hal ini perlu dilakukan agar atlet dapat mengetahui informasi ini untuk mempersiapkan kompetisi 
dengan lebih baik atau untuk mengantisipasi kemungkinan perubahan kinerja selama pertandingan atletik di mana kondisi lingkungan setempat berbeda dari kondisi di lokasi pelatihan mereka.

\section{METODE}

\section{Desain Penelitian}

Desain yang digunakan dalam penelitian ini adalah observasional study, dimana peneliti hanya melakukan observasi pada satu saat, tanpa memberikan intervensi pada variabel yang akan di teliti. Subjek dalam penelitian ini terdiri dari 80 Atlet PPLP se-Pulau Jawa. Diantaranya yaitu; Jawa Tengah (20 atlet), Jawa Timur (20 atlet), Jawa Barat (20 atlet) dan DIY Yogyakarta (20 atlet) dengan usia rata-rata $15.63 \pm 1,2$ tahun; tinggi, $167,9 \pm 7,5 \mathrm{~cm}$; dan berat, $60,5 \pm 9,1 \mathrm{~kg} ;$ FAT, $14,8 \pm 9,3 \%$; BMI, 21,7 \pm $5,9)$. Para peserta adalah atlet dari berbagai cabang olahraga. Peserta diminta untuk tidak mengubah kebiasaan diet mereka dan dilarang untuk melakukan aktivitas fisik dalam 24 jam sebelum tes.

Penelitian ini telah disetujui oleh Komisi Etik Penelitian Kesehatan POLTEKKES KEMENKES Bandung. Subjek penelitian diarahkan untuk mengisi informed consents jika memutuskan untuk berpartisipasi pada penelitian ini.

\section{Pengukuran dan Prosedur penelitian}

Empat tempat dengan iklim yang berbeda (suhu dan kelembaban) Jawa Barat $\left(23.4^{\circ} \mathrm{C} / 69 \%\right)$, Jawa Timur $\left(32.5^{\circ} \mathrm{C} / 60 \%\right)$, Jawa Tengah $\left(31.9^{\circ} \mathrm{C} / 50 \%\right)$, dan DIY Yogyakarta $\left(34.5^{\circ} \mathrm{C} / 70 \%\right)$ dipilih di setiap masingmasing daerah untuk di jadikan tempat penelitian. Di mana ke empat tempat tersebut diantaranya; Jawa Barat (Stadion Arcamanik), Jawa Timur (Stadion KONI Jawa Timur), Jawa tengah (Stadion Tri Lomba Juang), sedangkan untuk daerah DIY Yogyakarta (Stadion Mandala Krida). Untuk menilai suhu dan kelembaban peneliti menggunakan data yang diterbitkan oleh Badan Meteorologi Klimatologi dan Geofisika (BMKG) yang berada di daerah masing-masing. Sedangkan untuk berat badan $(\mathrm{kg})$ dan IMT diukur menggunakan OMRON Karada Scan HBF-375, sedangkan untuk 
penilaian tes kebugaran, peneliti menggunakan cooper test 2.4 kilometer dengan catatan waktu tercepat akan dikonversi ke tabel $\mathrm{VO}_{2 m a x}$.

Prosedur dalam penelitian ini yaitu peserta melakukan pengukuran awal (antropometri) terhadap tinggi badan, berat badan, lemak dan BMI. Selanjutnya perserta diperkenankan untuk tes $\mathrm{VO}_{2 \max }$ dengan menggunakan metode cooper test $2.4 \mathrm{KM}$.

\section{Analisis data}

Hasil data ditampilkan berupa rata-rata dan standar deviasi. Sebelum dianalisis signifikansi, pengujian normalitas menggunakan Kolmogorov-Smirnov Test. Analisis signifikan per kelompok menggunakan oneway ANOVA atau uji satu arah. Semua analisis statistik menggunakan aplikasi SPSS versi 22 dengan taraf signifikansi $(p<0.01$ atau $p<0.05)$.

\section{HASIL}

Dari hasil penelitian ini, peneliti menggunakan analisis satu arah atau uji oneway ANOVA untuk menguji signifikansi di antara variabel. Sebelum dianalisis signifikansi, pengujian normalitas menggunakan Kolmogorov-Smirnov Test dengan hasil bahwa data dari penelitian ini berdistribusi normal ( $p>0.05$ ). Selanjutnya, ditemukan bahwa rerata (SD) tinggi badan, berat badan, FAT, BMI, dari ke empat daerah tidak menunjukkan perbedaan yang signifikan. Namun pada penelitian ini, kami menemukan beberapa variabel yang siginifikan $(p<0.05)$ diantara keempat wilayah, variabel tersebut meliputi suhu dan kelembaban. Uji normalitas dapat di lihat pada tabel 1 sedangkan data antropometri, suhu, dan kelembaban dapat dilihat di tabel 2.

Tabel 1. Uji Normalitas

\begin{tabular}{lcccc}
\hline \multirow{2}{*}{ Variabel } & \multicolumn{4}{c}{ Uji Normalitas } \\
\cline { 2 - 5 } & $\begin{array}{c}\text { Kolomogrov- } \\
\text { smirnov }\end{array}$ & $P$-Value & Shapiro-wilk & $P$-Value \\
\hline Height $(\mathrm{cm})$ & 0.64 & 0.200 & 0.984 & 0.404 \\
Weight $(\mathrm{kg})$ & 0.68 & 0.200 & 0.984 & 0.439 \\
FAT $(\%)$ & 0.76 & 0.200 & 0.986 & 0.529 \\
BMI & 0.15 & 0.200 & 0.953 & 0.421
\end{tabular}

$\mathrm{P}>0.05=$ data berdistribusi normal, $\mathrm{P}<0.05=$ data tidak berdistribusi normal 
Pada tabel 1 menunjukkan bahwa data dari keempat variabel tersebut berdistribusi normal dengan nilai signifikansi $p>0.05$.

Tabel 2. Data Antropometri, Suhu, dan Kelembaban

\begin{tabular}{lcccccc}
\hline \multirow{2}{*}{ Variabel } & $\begin{array}{c}\text { Study Group } \\
\mathrm{N}=80\end{array}$ & $\begin{array}{c}\text { Jawa Barat } \\
(\mathrm{N}=20)\end{array}$ & $\begin{array}{c}\text { Jawa Timur } \\
(\mathrm{N}=20)\end{array}$ & $\begin{array}{c}\text { Jawa Tengah } \\
(\mathrm{N}=20)\end{array}$ & $\begin{array}{c}\text { Yogyakarta } \\
(\mathrm{N}=20)\end{array}$ & $P$-Value \\
\hline Height $(\mathrm{cm})$ & $167.94 \pm 94$ & $169.70 \pm 7.29$ & $166.60 \pm 7.73$ & $168.95 \pm 95$ & $166.50 \pm 9.75$ & 0.432 \\
Weight $(\mathrm{kg})$ & $60.59 \pm 9.19$ & $61.10 \pm 8.35$ & $59.61 \pm 8.24$ & $62.30 \pm 7.63$ & $59.35 \pm 12.24$ & 0.726 \\
FAT (\%) & $14.82 \pm 9.36$ & $13.10 \pm 2.55$ & $17.01 \pm 17.82$ & $14.60 \pm 2.18$ & $14.60 \pm 5.27$ & 0.625 \\
BMI & $21.72 \pm 5.96$ & $20.70 \pm 2.29$ & $21.38 \pm 1.86$ & $21.65 \pm 2.30$ & $23.15 \pm 11.41$ & 0.622 \\
Suhu & $30.59 \pm 4.77$ & $23.40 \pm 0.50$ & $32.50 \pm 3.66$ & $31.90 \pm 1.94$ & $34.55 \pm 0.82$ & $0.000^{*}$ \\
Kelembaban & $62.45 \pm 8.30$ & $69.80 \pm 0.52$ & $60.00 \pm 0.00$ & $50.00 \pm 0.00$ & $70.00 \pm 0.00$ & $0.000^{*}$ \\
\hline
\end{tabular}

Pada tabel 2 menunjukkan data $\mathrm{VO}_{2 m a x}$ dari keempat daerah dengan suhu dan kelembaban yang berbeda-beda, di mana hasil nilai dari $\mathrm{VO}_{2 \max }$ dilihat dari waktu tercepat peserta dalam menempuh jarak 2.4 kilometer, lalu di konsultasikan ke dalam tabel $\mathrm{VO}_{2 m a x}$. Dari ke empat daerah dengan suhu dan kelembaban yang berbeda terdapat perbedaan hasil rata-rata terhadap $\mathrm{VO}_{2 \max }$ di antara variabel $(\mathrm{P}<0.05)$.

Tabel 3. Data Correlation $\mathrm{VO}_{2 \max }$, Suhu dan Kelembaban

\begin{tabular}{cccccc}
\hline \multirow{2}{*}{ Variabel } & \multicolumn{5}{c}{ Suhu dan Kelembaban } \\
\cline { 2 - 6 } & $\begin{array}{c}\text { Jawa barat } \\
\left(23^{\circ} \mathrm{C} / 69 \%\right)\end{array}$ & $\begin{array}{c}\text { Jawa Timur } \\
\left(32^{\circ} \mathrm{C} / 60 \%\right)\end{array}$ & $\begin{array}{c}\text { Jawa Tengah } \\
\left(31^{\circ} \mathrm{C} / 50 \%\right)\end{array}$ & $\begin{array}{c}\text { Yogyakarta } \\
\left(34^{\circ} \mathrm{C} / 70 \%\right)\end{array}$ & $P$-Value \\
\hline $\mathrm{VO}_{2 \max }$ & $49.81 \pm 6.41$ & $47.80 \pm 6.81$ & $49.33 \pm 5.30$ & $46.04 \pm 6.79^{*}$ & 0.043
\end{tabular}

\section{PEMBAHASAN}

Ada beberapa temuan penting dari penelitian ini, termasuk $\mathrm{VO}_{2 \max }$ dapat berkurang pada suhu dan kelembaban $34^{\circ} \mathrm{C} / 70 \%$ dan $32^{\circ} \mathrm{C} / 60 \%$ dibandingkan dengan suhu dan kelembaban $23^{\circ} \mathrm{C} / 69 \%$ dan $31^{\circ} \mathrm{C} / 50 \%$. Namun, suhu dan kelembaban yang tinggi dalam kelompok atlet PPLP kami tampaknya beriringan dengan menurunnya $\mathrm{VO}_{2 \text { max }}$ yang diamati pada keempat daerah dengan suhu dan kelembaban yang berbeda. Hasil kami mendukung penelitian sebelumnya yang dilakukan oleh (Cheuvront et al., 2010) dalam hal ini $\mathrm{VO}_{2 m a x}$ menurun di lingkungan dengan suhu dan kelembaban yang tinggi. Temuan gangguan kinerja aerobik dalam panas bukanlah konsep baru. Namun, penelitian ini adalah salah satu yang pertama yang secara sistematis menyelidiki efek dari 
lingkungan yang panas dengan suhu dan kelembaban berbeda pada ke empat daerah di pulau Jawa Indonesia terhadap perubahan $\mathrm{VO}_{2 m a x}$.

Efek dari lingkungan yang panas pada kinerja aerobik belum didokumentasikan dengan baik (Park, Bae, Lee, \& Kim, 2012). Selain itu, hanya ada beberapa studi yang menyelidiki $\mathrm{VO}_{2 \max }$ pada tingkat kelembaban yang berbeda di lingkungan yang panas (Backx, Mc Naughton, Crickmore, Palmer, \& Carlisle, 2000). Studi tersebut menunjukkan adanya penurunan $\mathrm{VO}_{2 \max }$ yang signifikan terhadap partisipan yang berolahraga dalam lingkungan hipertermik dimana hal ini terjadi ketika regulasi panas dalam tubuh tidak dapat beradaptasi dengan panas yang ada di lingkungan sekitar $(p<0,05)$ dibandingkan dengan kondisi kontrol, kondisi panas-kering dan panas-basah memiliki tingkat konsumsi oksigen maksimal yang lebih rendah $(p<0,05)$. Kinerja aerob sangat dipengaruhi oleh fungsi kardiovaskular. Lingkungan yang panas dapat meningkatkan aliran pembuluh darah pada kulit, sehingga dapat mengubah fungsi kardiovaskular.

Peningkatan aliran pembuluh darah pada kulit tersebut mengurangi tekanan pada pembuluh darah pusat (sentral) dan mengganggu aliran darah dalam otot (Podrabsky, Stillman, \& Tomanek, 2015). Keluarnya keringat pada kondisi suhu yang meningkat dapat melebihi asupan cairan yang ada dalam tubuh. Ketika dehidrasi melebihi $3 \%$ dari total air tubuh ( $2 \%$ dari massa tubuh) maka kinerja aerobik secara konsisten dapat terganggu. Dehidrasi menambah hipertermia dan pengurangan volume plasma, yang bergabung untuk menonjolkan tekanan kardiovaskular dan hal ini dapat mengurangi $\mathrm{VO}_{2 \max }$ (Sawka, Cheuvront, \& Kenefick, 2012). Selain itu dehidrasi juga memiliki efek negatif pada respons fisiologis (misalnya, perubahan level denyut nadi, jumlah keringat yang dikeluarkan dan tanda-tanda kelelahan lainnya) yang dapat mengurangi kecepatan berlari (Camboni, Philipp, Schebesch, \& Schmid, 2008). Ada banyak penelitian yang melaporkan perubahan volume plasma yang lebih besar setelah latihan intensif (Göbölös et al., 2014). studi lain juga menunjukkan bahwa perubahan volume plasma 
darah yang tinggi di sebabkan karena durasi latihan yang lebih lama (yaitu, periode waktu lebih dari satu jam) (Crewe, Tucker, \& Noakes, 2008). Sebaliknya, protokol pengujian penelitian ini kurang dari 15 menit. Namun, penulis mengamati adanya penurunan $\mathrm{VO}_{2 \max }$ dalam kondisi suhu dan kelembaban yang tinggi dibandingkan dengan kondisi suhu dan kelembaban yang rendah. Temuan ini mungkin karena tekanan kardiovaskular yang diinduksi oleh meningkatnya suhu dan kelembaban di suatu daerah sehingga penelitian ini sejalan dengan penelitian yang dilakukan oleh (Mintarto \& Fattahilah, 2019).

\section{Kesimpulan}

Studi ini menunjukkan bahwa $\mathrm{VO}_{2 \max }$ dapat mengalami penurunan dengan seiringnya peningkatan suhu dan kelembaban udara di suatu daerah. Pada suhu ruangan tinggi, tubuh mengalami peningkatan, suhu tubuh lebih tinggi dan tekanan terhadap kardiovaskuler lebih tinggi sehingga mengakibatkan proses dehidrasi lebih tinggi sebagai bentuk perlawanan terhadap peningkatan suhu tersebut. Oleh karena itu, suhu yang tinggi dapat berpengaruh terhadap penurunan $\mathrm{VO}_{2 \max }$. Selain itu dehidrasi juga memiliki efek negatif pada respons fisiologis dan dapat mengurangi kecepatan berlari.

\section{Ucapan Terima Kasih}

Terimakasih kepada KEMENRISTEK DIKTI yang telah mendanai seluruh penelitian ini dan kepada seluruh Instansi Pemerintah baik itu Dinas Pemuda dan Olahraga (DISPORA) maupun Komite Olahraga Nasioanal Indonesia (KONI) di setiap daerah yang sudah mengizinkan kami dalam pengambilan data penelitian.

\section{REFERENSI}

Arngrímsson, S. Á., Petitt, D. S., Borrani, F., Skinner, K. A., \& Cureton, K. J. (2004). Hyperthermia and maximal oxygen uptake in men and women. European Journal of Applied Physiology, 92(4-5), 524532. https://doi.org/10.1007/s00421-004-1053-1

Backx, K., Mc Naughton, L., Crickmore, L., Palmer, G., \& Carlisle, A. (2000). Effects of differing heat and humidity on the performance 
and recovery from multiple high intensity, intermittent exercise bouts. International Journal of Sports Medicine, 21(6), 400-405. https://doi.org/10.1055/s-2000-3833

Camboni, D., Philipp, A., Schebesch, K.-M., \& Schmid, C. (2008). Accuracy of core temperature measurement in deep hypothermic circulatory arrest. Interactive CardioVascular and Thoracic Surgery, 7(5), 922-924. https://doi.org/10.1510/icvts.2008.181974

Cheuvront, S. N., Kenefick, R. W., Montain, S. J., \& Sawka, M. N. (2010). Mechanisms of aerobic performance impairment with heat stress and dehydration. Journal of Applied Physiology, 109(6), 19891995. https://doi.org/10.1152/japplphysiol.00367.2010

Crewe, H., Tucker, R., \& Noakes, T. D. (2008). The rate of increase in rating of perceived exertion predicts the duration of exercise to fatigue at a fixed power output in different environmental conditions. European Journal of Applied Physiology, 103(5), 569-577. https://doi.org/10.1007/s00421-008-0741-7

Gisolfi, C. V. (1983). Temperature regulation during exercise: Directions1983. Medicine and Science in Sports and Exercise, 15(1), 15-20. https://doi.org/10.1249/00005768-198315010-00006

Göbölös, L., Philipp, A., Ugocsai, P., Foltan, M., Thrum, A., Miskolczi, S., Ohri, S. K. (2014). Reliability of different body temperature measurement sites during aortic surgery. Perfusion (United Kingdom), 29(1),

75-81. https://doi.org/10.1177/0267659113497228

Mintarto, E., \& Fattahilah, M. (2019). Efek Suhu Lingkungan Terhadap Fisiologi Tubuh pada saat Melakukan Latihan Olahraga. JSES: Journal of Sport and Exercise Science, 2(1), 9-13.

Park, S. G., Bae, Y. J., Lee, Y. S., \& Kim, B. J. (2012). Effects of rehydration fluid temperature and composition on body weight retention upon voluntary drinking following exercise-induced dehydration. Nutrition Research and Practice, 6(2), 126-131. https://doi.org/10.4162/nrp.2012.6.2.126

Podrabsky, J. E., Stillman, J. H., \& Tomanek, L. (2015). Biochemical adaptation: Unity in principles, diversity in solutions. Journal of Experimental Biology, 218(12), 1797-1798. https://doi.org/10.1242/jeb.124479

Sacha, J. J., \& Quinn, J. M. (2011). The environment, the airway, and the athlete. Annals of Allergy, Asthma and Immunology, 106(2), 81-87. https://doi.org/10.1016/j.anai.2010.06.004

Sandi, I. N. (2014). Pengaruh Suhu Dan Kelembaban Relatif Udara Terhadap Penampilan Fisik Dalam Olahraga. Seminar Nasional Prodi Biologi F. MIPA UNHI, 282-287. Retrieved from http://digilib.mercubuana.ac.id/manager/t!@file_artikel_abstrak/lsi_ Artikel_730549414152.pdf 
Sawka, M. N., Cheuvront, S. N., \& Kenefick, R. W. (2012). High skin temperature and hypohydration impair aerobic performance. Experimental Physiology, 97(3), 327-332. https://doi.org/10.1113/expphysiol.2011.061002

Snell, P. G., Stray-Gundersen, J., Levine, B. D., Hawkins, M. N., \& Raven, P. B. (2007). Maximal oxygen uptake as a parametric measure of cardiorespiratory capacity. Medicine and Science in Sports and Exercise, $39(1)$, 103-107. https://doi.org/10.1249/01.mss.0000241641.75101.64

Stensrud, T., Berntsen, S., \& Carlsen, K. H. (2006). Humidity influences exercise capacity in subjects with exercise-induced bronchoconstriction (EIB). Respiratory Medicine, 100(9), 16331641. https://doi.org/10.1016/j.rmed.2005.12.001

Taylor, C. A., Cheng, C. P., Espinosa, L. A., Tang, B. T., Parker, D., \& Herfkens, R. J. (2002). In vivo quantification of blood flow and wall shear stress in the human abdominal aorta during lower limb exercise. Annals of Biomedical Engineering, 30(3), 402-408. https://doi.org/10.1114/1.1476016

Tyka, A., Palka, T., Tyka, A., Cison, T., \& Szygula, Z. (2009). The influence of ambient temperature on power at anaerobic threshold determined based on blood lactate concentration and myoelectric signals. International Journal of Occupational Medicine and Environmental Health, 22(1), 1-6. https://doi.org/10.2478/v10001009-0005-8

Zhao, J., Lorenzo, S., An, N., Feng, W., Lai, L., \& Cui, S. (2013). Effects of heat and different humidity levels on aerobic and anaerobic exercise performance in athletes. Journal of Exercise Science and Fitness, 11(1), 35-41. https://doi.org/10.1016/j.jesf.2013.04.002 